\title{
MULTIPERFORMANCE OPTIMIZATION OF TENSILE STRENGTH AND HEAT INPUT OF LASER TRANSFORMATION HARDENING OF COMMERCIALLY PURE TITANIUM USING TAGUCHI METHODOLOGY AND UTILITY CONCEPT
}

\author{
Duradundi Sawant Badkar*; Krishna Shankar Pandey** \& Buvanashekaran, G. ${ }^{* *}$ \\ ${ }^{*}$ Corresponding Author, Holy-wood's Academy, Sanjeevan Engineering \& Technology \\ Institute, Panhala-416201, District: Kolhapur, Maharashtra, India \\ ${ }^{* * N a t i o n a l ~ I n s t i t u t e ~ o f ~ T e c h n o l o g y, ~ T i r u c h i r a p p a l l i-620 ~ 015, ~ T a m i l ~ N a d u, ~ I n d i a ~}$ \\ ***Welding Research Institute, Bharat Heavy Electricals Limited, Tiruchirappalli-620 014, \\ Tamil Nadu, India \\ E-mail: dsbadkar_2007@yahoo.co.in;kspmet@yahoo.co.in; gbs@bheltry.co.in
}

\begin{abstract}
:
Purpose of this paper: The main objective of this research paper is to investigate and evaluate the optimal values of laser process parameters: laser power, scanning speed, and focused position for the simultaneous minimization and maximization of heat input and tensile strength respectively by Taguchi method and utility concept approach in laser transformation hardening of commercially pure titanium sheet of $1.6 \mathrm{~mm}$ thickness using continuous wave (CW) Nd:YAG laser beam. Design/methodology/approach: The effect of laser process parameters on the heat input and tensile strength properties of commercially pure titanium and subsequent optimal settings of the parameters have been obtained using Taguchi's parametric design approach and utility concept. The response performance is analyzed based on signal-to-noise ratio and analysis of variance (ANOVA). The optimal levels of the laser process parameters were determined through the Analysis of Means (ANOM). Findings: The optimization results revealed that a combination of higher levels of scanning speed and focused position i.e., increase in defocus along with laser power in the lower level play important role in order to simultaneously minimize the heat input and to maximize the tensile strength $(\sigma)$. The predicted optimal values of tensile strength and heat input of commercially pure titanium sheet produced by laser transformation hardening process are $464 \mathrm{~N} / \mathrm{mm}^{2}$ and 141.667 Watts, respectively, for the optimized laser process parameters with minimum LP=750 Watts, maximum $S S=3000 \mathrm{~mm} / \mathrm{min}$, and lower value of $\mathrm{FP}=-30 \mathrm{~mm}$ (increase in defocus). Research limitations/implications: Research range is limited to investigation of optimization laser hardening process parameters for the simultaneous minimization and maximization of heat input and tensile strength respones.of commercially pure titanium. Hardness test responses are also be optimized in future research work. Practical implications: Laser transformation hardening is an innovative and advanced laser surface modification technique has been employed in aerospace, marine, chemical applications, heat exchangers, cryogenic vessels, components for chemical processing and desalination equipment, condenser tubing, airframe skin, and nonstructural components which introduces the advantageous residual stresses into the surface, improving the mechanical properties like wear, resistance to corrosion, tensile strength, and fatigue strength. Originality/value: Authors made an effort to optimize the laser process parameters in order to minmize the heat input and maximize tensile strength of laser transformation hardening of commercially pure titanium using Taguchi methodology and utility concept.
\end{abstract}

Key Words: LTH, Nd:YAG Laser, Taguchi Methodology, Tensile Strength, Heat Input 


\section{INTRODUCTION}

Titanium and its alloys are extensively used in the aeronautical industry, medicine and engineering industry due to their specific properties such as light weight, high strength-to weight ratio, corrosion resistance and excellent high temperature properties. Surface engineering of titanium alloy components provides means by which the desirable bulk properties may be retained in conjunction with enhanced wear resistance [1,2]. The low density, excellent high temperature mechanical properties and good corrosion resistance of titanium and titanium alloys have led to a diversified range of successful applications for the demanding performance and reliability requirements of the medical, aerospace, automotive, petrochemical, nuclear and power generation industries [3, 4].

The standard laser transformation hardening of titanium and its alloys involves two main steps: beta phase formation, in which the material is heated to/above the beta transus temperature, i.e., $\beta$-transus $\left(888^{\circ} \mathrm{C}\right.$ or $\left.1621^{\circ} \mathrm{F}\right)$, in order to form the material with $100 \%$ beta phase (but below the melting point) and "self quenching" or cooling down, where $\beta$-phase is transformed into harder acicular (plate-like) a martensite (transformed $\beta$ ) or retain beta to room temperature. The $\beta$-transus is defined as the lowest equilibrium temperature at which the material is $100 \%$ beta or alpha, which does not exist. The $\beta$-transus is critical in deformation processing and in heat treatment. A correct treatment requires the heating stage be long enough for the $\beta$-phase formation to complete and allow the alloying elements such as, manganese, carbon, oxygen and nitrogen to stabilize it and dissolve iron, vanadium, molybdenum, copper, nickel, and silicon into the matrix. Self quenching should be fast enough so as to suppress the normal breakdown of $\beta$-phase into the initial $\alpha$ or $\alpha+\beta$ phases and produce martensite instead [5].

Many papers have been published demonstrating laser welding in predicting optimal laser welding parameters for the simultaneous optimization of laser welded bead profile parameters and tensile strength using Taguchi's approach of design of experiments. But there in no such literature and research papers are not available considering the optimization of laser hardening parameters when designing the heat input and tensile strength of titanium and its alloys by applying Taguchi's method. However, an attempt has been made here to optimize the heat input and tensile strength of laser transformation hardening of commercially pure titanium using Taguchi methodology and utility concept.

The following authors have been published the papers on process optimization of laser beam welding parameters and tensile strength of steels, magnesium alloy, aluminium alloy, acrylics etc using Taguchi's approach and utility concept. G. Padmanaban et al. [6] developed an empirical relationship to predict tensile strength of the laser beam welded AZ31B magnesium alloy by incorporating process parameters such as laser power, welding speed and focal position by conducting experiments based on a three factor, three level, central composite face centered design matrix with full replications technique. I. Jang1 et al. [7] presented a methodology to predict and optimize the ultimate tensile strength of 6061-T6 aluminium (Al) alloy under a laser-GMA hybrid welding process. Kamal Kumar Kanaujia et al. [8] successfully used analyses of variance (ANOVA), signal-to-noise ( $S / N)$ ratio of Taguchi approach for optimizing the Nd:YAG laser welding process parameters. Anawa, E.M et al. [9] applied the Taguchi method for designing the experimental and mathematical models to predict the Optimization of dissimilar joining of titanium/aluminum. They developed mathematical models for optimising the welding pool geometry of joints. $E$ Anawa and a Olabi et al. [10] has recently been successfully used a statistical design of experiment (DOE), analyses of variance (ANOVA) and Taguchi approach to optimize selected LBW parameters for the production of F/A joints. B Acherjee et al. [11] used Taguchi method of parameter design as a statistical design of experiment technique to set the optimal process parameters of laser transmission welding of acrylics. Tsung Yuan Kuo et al. [12] studied the relative tensile strength of weld and base metal as a quality factor for the Taguchi analysis in laser beam welding of stainless steel. Hsuan Liang Lin et al. [13] adopted Taguchi method to perform the initial optimization of the pulsed Nd:YAG laser micro-weld process parameters. In a similar manner the authors here made an attempt to apply the Taguchi's approach and 
utility concept for optimizing the laser hardening process parameters for simultaneous optimization of heat input and tensile strength of commercially pure titanium.

This paper illustrates the application of Taguchi method using the utility concept for multiobjective laser transformation hardening process optimization. The aim of this paper is to investigate and evaluate the optimal values of laser process parameters, such as laser power (LP), scanning speed (SS), and focused position (FP) for the simultaneous minimization and maximization of heat input and maximize the tensile strength respectively by Taguchi method and utility concept approach in laser transformation hardening of commercially pure titanium sheet of $1.6 \mathrm{~mm}$ thickness using continuous wave (CW) Nd:YAG laser beam.

\section{EXPERIMENTAL METHODOLOGY}

\subsection{Taguchi Approach}

The performance of a product or process is characterized in terms of design and noise factors. Taguchi method utilizes a special design of orthogonal arrays to study the entire parameter space with only a small number of experiments. Experimental design using orthogonal arrays (OAs), recommended by Taguchi, not only minimize the number of treatments for each trial, but also keep the pair-wise balancing property. An OA is basically a matrix of rows and columns in which columns are assigned factors or their interactions and rows represent the levels of various factors for a particular experimental trial. The treatment combinations are chosen to provide sufficient information to determine the factor effects using the analysis of means. The orthogonal array imposes an order on the way the experiment is carried out. The purpose of the Taguchi method is to identify the "optimal" settings of the controllable factors, not only to improve the product or process, but also to reduce the influence of the noise factors $[14,15]$.

The first step of designing an experiment with known number of factors in Taguchi's method is to select a most suitable OA, which design to cover all the possible experiment conditions and factor combination. The selection of which OA to use predominantly depends on these items in order of priority [16]:

1) The number of factors and interactions of interest,

2) The number of levels for the factors of interest, and

3) The desired experimental resolution or cost limitations.

To select a suitable orthogonal array for experiments, the total degrees of freedom need to be calculated.

Basically, the degrees of freedom for the OA should be greater than or at least equal to those for the design factors. Once the levels of design factors have been settled, the Analysis of Means (ANOM) is conducted to find interaction of each factor on the objective value by calculating the mean of entire data of the design factors. Hence, the optimum level of each design factor can be found by focusing on its corresponding response graph. The Analysis of Variance (ANOVA) is then performed to determine the significant factors for the selected criterion. Finally, a prediction model consisting of the significant factors is built and confidence interval for estimated mean is constructed.

The performance measure, signal to noise ratio $(\mathrm{S} / \mathrm{N})$ proposed by Taguchi is used to obtain the optimum process parameter combinations. The larger $\mathrm{S} / \mathrm{N}$ means the relation to the quality will become better [17]. The lower quality characteristic will be regarded as a better result when considering the smaller-the-best quality. The related $\mathrm{S} / \mathrm{N}$ ratio is defined $[18,19]$ as:

$$
S / N \text { ratio }=-10\left(\log \sum_{i=1}^{n} \frac{y_{i}^{2}}{n}\right)
$$

where, $\mathrm{n}$ is the number of experiments for each experimental set and $y_{i}$ expresses the quality experiment characteristic at the $\mathrm{i}$-th experiment. On the contrary, the larger quality characteristic will have better result t when considering the larger-the-best quality; therefore, 
by taking the inverse of quality characteristic into Equation (1), the related $\mathrm{S} / \mathrm{N}$ ratio can also be deduced and shown in Equation (2) $[18,19]$.

$$
S / N \text { ratio }=-10\left(\log \sum_{i=1}^{n} \frac{1 / y_{i}^{2}}{n}\right)
$$

\subsection{Taguchi Approach with Utility Concept}

In order to optimize the multiple responses, Taguchi design is not applied directly, as each performance characteristic may not have the same measurement unit. Hence, the evaluations of various characteristics should be combined to give a composite index. Such a composite index represents the utility of a product. The overall utility of a product is the sum of utilities of each of the performance quality characteristics [20, 21]. If $X_{i}$ is a measure of effectiveness of an attribute $i$ and there are $n$ attributes evaluating the outcome space, then the overall utility function is given by:

$$
U\left(X_{1}, X_{2}, \ldots . X_{n}\right)=\sum_{i=1}^{n} U_{i}\left(X_{i}\right)
$$

where, $U_{i}\left(X_{i}\right)$ is the utility of the ith attribute. Depending upon the requirements, the attributes may be given priorities and weights. Hence, the weighted form of Equation (3) is:

$$
U\left(X_{1}, X_{2}, \ldots . X_{n}\right)=\sum_{i=1}^{n} \omega_{i} U_{i}\left(X_{i}\right)
$$

where, $\quad \sum_{i=1}^{n} \omega_{i}=1$, and $\omega_{i}$ is the weight assigned to attribute $\mathrm{i}$.

\section{EXPERIMENTAL PROCEDURE}

\subsection{Plan of Experiments}

The experimental bead on trials were conducted on given commercially pure titanium of 1.6 $\mathrm{mm}$ thickness base material with chemical composition nearer to ASTM Gr. 3 as shown in Table I. Before conducting the experiments on the substrate, initially the materials surface is cleaned properly with suitable agents.

Table I: Chemical composition of commercially pure Titanium.

\begin{tabular}{|c|c|c|c|c|c|c|c|c|c|}
\hline Element & Titanium & $\mathrm{C}$ & $\mathrm{Fe}$ & $\mathrm{Mo}$ & $\mathrm{H}$ & $\mathrm{Zr}$ & $\mathrm{O}$ & $\mathrm{N}$ & $\mathrm{Ti}$ \\
\hline \% by Weight & Balance & 0.10 & 0.20 & 0.003 & 0.015 & 0.0039 & 0.16 & 0.003 & Balance \\
\hline
\end{tabular}

In this study a $2 \mathrm{~kW}$, continuous wave (CW) mode Nd:YAG laser beam device from $\mathrm{GSI}$ Lumonics is used as machining tool. Unlike the $10.6 \mu \mathrm{m}$ wavelength of the $\mathrm{CO}_{2}$ laser beam, the wavelength of the Nd:YAG laser beam is only $1.064 \mu \mathrm{m}$. The low beam energy prevents the surface of the hardening area from overheating and ensures that the heat affected zone is small.

The experiment was carried out according to the Taguchi's L9 orthogonal array methodology design. A spherical beam configuration is used throughout for the study. The laser beam is transported through a fibre optic cable to the work centre. Siemens 802 CNC controller is providing the process control during the experiments. The work centre is having $\mathrm{x}, \mathrm{y}$ and rotational movement for processing applications. The laser source, work centre and the controls are interfaced. Cooling is ensured by a chiller and a cooling tower. For the study, $120 \mathrm{~mm}$ focal optic is employed with varying beam spot size (i.e., focused position from -10, $20,-30 \mathrm{~mm}$ ) depending on defocus distance to obtain a wider scan area. Argon gas is employed as shielding medium with a constant flow rate of $10 \mathrm{lpm}$ throughout the experimental work. Transverse sectioned specimens were cut from laser hardened bead-on trial of commercially pure Titanium sheet having $1.6 \mathrm{~mm}$ thickness and mounted. Standard metallographic was made for each transverse sectioned specimens. 
For the microstructure observation, the transverse section cut laser hardened specimens were ground with $\mathrm{SiC}$ paper up to 1500 grit, and then polished by $1 \mu \mathrm{m} \mathrm{Al}_{2} \mathrm{O}_{3}$ powder. The microstructure of the hardened surface observed using an optical microscope (with image processing computer controlled software) with digital micrometers attached to it with an accuracy of $0.001 \mathrm{~mm}$, which allow to measure in x-axes and y-axes after the polished surface was acid etched by a solution of: Kroll's reagent-10ml of $\mathrm{HF}, 5 \mathrm{ml} \mathrm{HNO}_{3}, 85 \mathrm{ml}$ water; Procedure: Swab 3 to 20 seconds.

In the present work, three parameters, namely, laser power (LP), scanning speed (SS), and focused position (FP) are considered and the ranges of $750-1250 \mathrm{~W}, 1000-3000 \mathrm{~mm} / \mathrm{min}$, and -10 to $-30 \mathrm{~mm}$ respectively. The parameters identified in the present study are multilevel factors and their outcome effects are not linearly related; and hence, it has been decided to use three-level tests for the laser process parameters. The identified process parameters and their design levels are presented in Table II.

Taguchi optimization begins with the selection of orthogonal array with distinct number of levels defined for each of the parameters, laser power, scanning speed, and focused position. The minimum number of trials in the orthogonal array is given by:

$$
N_{\text {min }}=(l-1) k+1
$$

where, $k=$ number of factors $=3$ and $I=$ number of levels $=3$. This gives $N_{\min }=7$; and hence, according to Taguchi design concept L9 orthogonal array has been selected. Thus, only 9 experiments are required to study the entire laser transformation hardening process parameters space using L9 orthogonal array. The L9 orthogonal array along with the process parameters used for the present study is illustrated in Table III.

Table II: Process parameters and experimental design levels used.

\begin{tabular}{|c|c|c|c|c|l|}
\hline \multirow{2}{*}{ Parameters/factors } & \multirow{2}{*}{ Code } & \multirow{2}{*}{ Unit } & \multicolumn{3}{|c|}{ Levels } \\
\cline { 4 - 6 } & & & 1 & 2 & 3 \\
\hline Laser power & LP & Watts & 750 & 1000 & 1250 \\
Scanning speed & SS & $\mathrm{mm} / \mathrm{min}$ & 1000 & 2000 & 3000 \\
Focused position & FP & $\mathrm{mm}$ & -10 & -20 & -30 \\
\hline
\end{tabular}

Table III: L9 orthogonal array along with the responses and computed values of multiresponse $\mathrm{S} / \mathrm{N}$ ratio.

\begin{tabular}{|c|c|c|c|c|c|c|c|c|}
\hline \multirow{2}{*}{$\begin{array}{l}\text { Seria } \\
\text { I No }\end{array}$} & \multicolumn{3}{|c|}{ Levels of process parameters } & \multicolumn{2}{|c|}{ Responses } & \multicolumn{3}{|c|}{$\mathrm{S} / \mathrm{N}$ ratio, $\mathrm{dB}$} \\
\hline & $\begin{array}{c}\text { LP, } \\
\text { Watts }\end{array}$ & $\begin{array}{c}\mathrm{SS}, \\
\mathrm{mm} / \mathrm{min}\end{array}$ & $\begin{array}{l}\mathrm{FP}, \\
\mathrm{mm}\end{array}$ & $\begin{array}{l}\mathrm{HI}, \\
\mathrm{J} / \mathrm{cm}\end{array}$ & $\begin{array}{c}\sigma, \\
\mathrm{N} / \mathrm{mm}^{2}\end{array}$ & $\eta_{1}$ for $\mathrm{HI}$ & $\eta_{2}$ for $\sigma$ & $\begin{array}{c}\text { Multiresponse } \\
\eta\end{array}$ \\
\hline 1 & 1 & 1 & 1 & 450 & 444 & -53.06 & 52.9477 & -0.0583 \\
\hline 2 & 1 & 2 & 2 & 225 & 457 & -47.04 & 53.1983 & 3.0773 \\
\hline 3 & 1 & 3 & 3 & 150 & 462 & -43.52 & 53.2928 & 4.8855 \\
\hline 4 & 2 & 1 & 2 & 600 & 442 & -55.56 & 52.9084 & -1.3273 \\
\hline 5 & 2 & 2 & 3 & 300 & 453 & -49.54 & 53.122 & 1.7898 \\
\hline 6 & 2 & 3 & 1 & 200 & 459 & -46.02 & 53.2363 & 3.6078 \\
\hline 7 & 3 & 1 & 3 & 750 & 440 & -57.50 & 52.8691 & -2.3161 \\
\hline 8 & 3 & 2 & 1 & 375 & 448 & -51.48 & 53.0256 & 0.7725 \\
\hline 9 & 3 & 3 & 2 & 250 & 455 & -47.96 & 53.1602 & 2.6007 \\
\hline
\end{tabular}

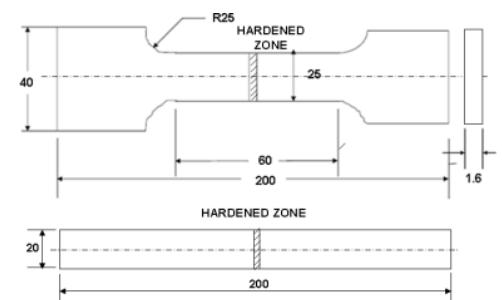

Figure 1: Schematic sketch of tensile test specimen, as per AWS B4.0.

The schematic diagram of specimens which are used for tensile test and their dimensions are given in Figure 1. All the specimens were obtained in the same orientation from the laser hardened plate. The single pass laser beam transformation hardening experiments were 
conducted on a given commercially pure (CP Ti) or commercially pure titanium substrate. The thickness of the substrate selected is $1.6 \mathrm{~mm}$, to stimulate the majority of industrial applications that is in practice at present.

\section{ANALYSIS OF RESULTS AND DISCUSSION}

In the present study of laser transformation hardening process optimization, the objective is to minimize the heat input and to maximize the tensile strength. The laser heat input $(\mathrm{HI})$ is directly related to the laser power (LP) and scanning speed (SS). It can be calculated directly from the heat input $(\mathrm{HI})=\mathrm{LP} / \mathrm{SS}$. The experimental values of heat input $\mathrm{HI}$ ) and tensile strength $(\sigma)$ for each trial of an orthogonal array are summarized in Table III.

Taguchi design and utility concept employs $\mathrm{S} / \mathrm{N}$ ratio instead of mean value to interpret the trial results data into a value for the evaluation characteristic in the optimum laser parameters setting analysis, because $\mathrm{S} / \mathrm{N}$ ratio can replicates both mean and variation of the performance characteristics. In the present investigation, Taguchi parameter design with the utility concept has been introduced for optimizing the multiple performance characteristics $(\mathrm{HI}$ and $\sigma$ ). Here, heat input $(\mathrm{HI})$ is to be minimized and tensile strength $(\sigma)$ to be maximized. Hence, "smaller the better type" characteristic for $\mathrm{HI}$ and "larger the better type" characteristic for $\sigma$ have been selected. The S/N ratio associated with the responses, $\mathrm{HI}$ and $\sigma$ are given as:

$$
\begin{aligned}
& \eta_{1}=-10 \log _{10}\left(H I^{2}\right) \\
& \eta_{2}=-10 \log _{10}\left[\frac{1}{\sigma^{2}}\right]
\end{aligned}
$$

In the utility concept, the multiresponse $\mathrm{S} / \mathrm{N}$ ratio is given by [22]:

$$
\eta=\omega_{1} \eta_{1}+\omega_{2} \eta_{2}
$$

where, $\omega_{1}$ and $\omega_{2}$ are the weighting factors associated with $\mathrm{S} / \mathrm{N}$ ratio for each of the responses $\mathrm{HI}$ and $\sigma$, respectively. These weighting factors are decided based on the priorities among the various responses to be simultaneously optimized. In the present investigation, weighting factors of 0.5 for each of the responses is considered, which gives equal priorities to both $\mathrm{HI}$ and $\sigma$ for simultaneous optimization. The computed values of $\mathrm{S} / \mathrm{N}$ ratio for each response and the multiresponse $\mathrm{S} / \mathrm{N}$ ratio for each trial in the orthogonal array are given in Table III.

\subsection{Analysis of Interaction Effects of Parameters on Multiple Performance Characteristics}

The plots of two factor interaction effects on multiresponse $\mathrm{S} / \mathrm{N}$ ratio of multiple characteristics are shown in Figure 2-4. Figure 2 shows the interaction effect of scanning speed and laser power. It can be observed from Figure 1 that there exists a considerable interaction effect of scanning speed variation on multiresponse $\mathrm{S} / \mathrm{N}$ ratio of performance characteristics for any given value of laser power. On the other hand, for any given laser power, the effect of scanning speed variation on multiresponse $\mathrm{S} / \mathrm{N}$ ratio is comparatively less. Further, when the scanning speed is high (3000 $\mathrm{m} / \mathrm{min})$, the interaction effect due laser power is more as compared to the interaction effect when the scanning speed is either at low level $(1000 \mathrm{~m} / \mathrm{min})$ or at medium level $(2000 \mathrm{~m} / \mathrm{min})$. However, the interaction effect of scanning speed at $3000 \mathrm{~mm} / \mathrm{min}$ is high for all the laser power process levels and at $2000 \mathrm{~mm} / \mathrm{min}$ is high for laser power 1000,1250 Watts as compared to the for the laser power 750 Watts scanning speed at $1000 \mathrm{~mm} / \mathrm{min}$ and $2000 \mathrm{~mm} / \mathrm{min}$. Figure 3 illustrates the interaction effect of laser power and focused position. From the figure it is seen that the degree of mutual interaction between laser power and focused position on multiresponse S/N ratio of performance characteristics is more except for the laser power at lower level of 750 Watts at focused position $-10 \mathrm{~mm}$. The interaction effect due to scanning speed and focused position is exhibited in Figure 4. Similarly in this case also, the degree of mutual interaction between scanning speed and focused position on multiresponse $\mathrm{S} / \mathrm{N}$ ratio of performance 
characteristics is more except for the scanning speed at lower level of $1000 \mathrm{~mm} / \mathrm{min}$ for the focused position $-30 \mathrm{~mm}$. Hence from the figures and above results it is evident that the interaction effect is minimal either due to laser power at 750 Watts or focused position at $30 \mathrm{~mm}$ when the scanning speed is $1000 \mathrm{~mm} / \mathrm{min}$ and $3000 \mathrm{~mm} / \mathrm{min}$.

Figure 6 shows the Average values of $\mathrm{S} / \mathrm{N}$ ratio of each process parameter at each level 1-3. The S/N ratio analysis (Figure 4) suggests that the lower level of LP and higher levels of SS and FP are the best optimum levels for achieving the minimum heat input and maximum tensile strength of laser hardened titanium with $1.6 \mathrm{~mm}$ thickness sheet.

\subsection{Analysis of Means}

The analysis of means (ANOM) is applied to establish the optimal process parametric settings and it is the process of estimating the main effects of each process parameter [23]. The effect of a parameter level is the deviation it causes from the overall mean response. The overall mean of associated with nine experiments is computed as:

$$
m=\frac{1}{9} \sum_{k=1}^{9} \eta_{k}
$$

The effect of a process parameter level $i$ for parameter $j$ is:

$$
(m)_{i, j}=\frac{1}{l} \sum_{i=1}^{l}\left(\eta_{i}\right)_{j}
$$

The optimum level of a process parameter is the level, which gives the highest $\mathrm{S} / \mathrm{N}$ ratio. The maximization of multiresponse $\mathrm{S} / \mathrm{N}$ ratio for the optimal level associated with each process parameter is:

$$
j_{i, o p t}=\max \left\{(m)_{i, j}\right\} \quad \text { For } j=L P, S S, F P ; \quad i=1,2,3
$$

The ANOM result for multiresponse $\mathrm{S} / \mathrm{N}$ ratio characteristics is represented in the response graph as represented in Figure 5. Thus, for the optimal process parameter setting for the present investigation is LP1, SS3 and FP3. Hence, the best combination values to accomplish the minimum heat input $(\mathrm{HI})$ and maximum tensile strength $(\sigma)$ are:

- Laser power (LP1): 750 Watts

- Scanning speed (SS3): $3000 \mathrm{~mm} / \mathrm{min}$

- Focused position (FP3): $-30 \mathrm{~mm}$.

However, the relative contribution of each process parameter on multiple performance characteristics is determined through ANOVA that enables more accurate determination of the optimal process parameter levels.

\subsection{Analysis of Variance}

Table IV illustrates the results of ANOVA performed on multiresponse $S / N$ ratio of performance characteristics. Analyzing the measured responses by the Design-expert software, the fit summary output indicates that the linear model is significantly significant for the models laser power and scanning speed except for the focused position value of "Probability > F" in Table IV is more than 0.0500 . The adequacy of the developed model for multiresponse $\mathrm{S} / \mathrm{N}$ ratio of performance characteristics were tested using the analysis of variance (ANOVA) technique and the results of the linear response surface model fitting in the form of analysis of variance (ANOVA) are given in Table IV. The test for significance of the regression model, the test for significance on individual model coefficients test was performed using the same statistical software package. The results from ANOVA are shown in Table IV. F ratio corresponding 95\% confidence level in calculation of three process parameters analysed from is accurately is $F_{0.05,2,8}=4.459$. From Table IV, it is apparent that the $F$-values of factor LP and factor SS, were all greater than $F_{0.05,2,8}=4.459$. And factor FP is not a significant affecting parameter for minimum heat input and maximum tensile strength. $F$-value of FP (0.807465) is less than $F_{0.05,2,8}=4.459$. Most significant parameter that effect the heat input and tensile strength is scanning speed SS followed by laser power (LP).

The same Table IV show also the other adequacy measures $R^{2}$, adjusted $R^{2}$ and predicted $R^{2}$. The coefficient of determination $R^{2}$ indicates the goodness of fit for the model. 
The values of "Probability > F" in Table IV is less than 0.0500 indicate that all model is significantly significant. The Model F-value of 48003.07 implies the model is significant. There is only a $0.01 \%$ chance that a "Model F-Value" this large could occur due to noise. In this case all laser process parameters LP, SS, FP are significant model terms. Values greater than 0.1000 indicate the model terms are not significant. The "Pred R-Squared" of 0.999859 is totally in reasonable agreement with the "Adj R-Squared" of 0.999972. "Adeq Precision" measures the signal to noise ratio. A ratio greater than 4 is desirable.The adequate precision ratio above 4 indicates adequate model discrimination. In this case the ratio of 653.1637 indicates an adequate signal.

It is clearly observed in ANOVA table that the scanning speed has major contribution $(82.61 \%)$ in optimizing the multiple performance characteristics followed by laser power $(17.38 \%)$ and focused position $5.60 \mathrm{E}-04 \%$. From the table it has been also confirmed that scanning speed is the most influencing factor as compared to the laser power. As SS decreases and LP increases results increase in the heat input and hence decrease in tensile strength. Besides, focused position has no significant effect on heat input as well as on tensile strength. Therefore, from the results it clear that only two factors scanning speed and laser power played important role in optimizing the heat input and tensile strength. Further, it is also seen that the ANOVA has resulted in around $6.95 \mathrm{E}-04 \%$ of error contribution, indicating that the interaction effects of the process parameters are negligible for simultaneously minimizing the heat input and maximizing tensile strength.

Table IV: ANOVA table for multiresponse S/N ratio linear Model.

\begin{tabular}{|c|c|c|c|c|c|c|c|}
\hline Source & $\begin{array}{c}\text { Sum of } \\
\text { Squares }\end{array}$ & df & $\begin{array}{c}\text { Mean } \\
\text { Square }\end{array}$ & $\begin{array}{c}F \\
\text { Value }\end{array}$ & $\begin{array}{c}\text { p-value } \\
\text { Prob }>F\end{array}$ & $\begin{array}{c}\text { Percentage } \\
\text { contribution }\end{array}$ \\
\hline Model & 45.17697 & 6 & 7.5295 & 48003.07 & $<0.0001$ & significant & 99.99 \\
\hline LP & 7.851928 & 2 & 3.92596 & 25029.34 & $<0.0001$ & & 17.38 \\
\hline SS & 37.32479 & 2 & 18.6624 & 118979.1 & $<0.0001$ & & 82.61 \\
\hline FP & 0.000253 & 2 & 0.00013 & 0.807465 & 0.5533 & & $5.60 \mathrm{E}-04$ \\
\hline Residual & 0.000314 & 2 & 0.00016 & & & & $6.95 \mathrm{E}-04$ \\
\hline Corrected Total & 45.17728 & 8 & & & & & 100.00 \\
\hline
\end{tabular}

\begin{tabular}{|c|c|c|c|}
\hline Std. Dev. & 0.01252 & R-Squared & 0.999993 \\
\hline Mean & 1.44799 & Adj R-Squared & 0.999972 \\
\hline C.V. $\%$ & 0.86493 & Pred R-Squared & 0.999859 \\
\hline PRESS & 0.00635 & Adeq Precision & 653.1637 \\
\hline
\end{tabular}

\subsection{Verification Test of Optimal Result}

Figure 7 shows the relationship between the computed or actual and predicted values of mutiresponse $\mathrm{S} / \mathrm{N}$ ratio. The figure indicates that the developed model is adequate because the residuals in prediction of each response are minimum values, since the residuals tend to be close to the diagonal line. Figure 8 shows the comparison of computed values with predicted values of multiresponse $\mathrm{S} / \mathrm{N}$ ratio of performance characteristics. From the figures it has been observed and ensured that predicted values are very closely agreement with the experimental values.

Table V: Confirmation of experiments.

\begin{tabular}{|c|c|c|c|c|c|c|c|c|}
\hline \multirow[b]{2}{*}{ Trial No } & \multicolumn{3}{|c|}{ Process parameters } & \multicolumn{2}{|c|}{ Responses } & \multicolumn{3}{|c|}{$\mathrm{S} / \mathrm{N}$ ratio, $\mathrm{dB}$} \\
\hline & $\begin{array}{l}\text { LP, } \\
\text { Watts }\end{array}$ & $\begin{array}{c}\mathrm{SS}, \\
\mathrm{mm} / \mathrm{min}\end{array}$ & $\begin{array}{l}\mathrm{FP}, \\
\mathrm{mm}\end{array}$ & $\begin{array}{c}\mathrm{HI} \text {, } \\
\mathrm{J} / \mathrm{cm}\end{array}$ & $\begin{array}{c}\sigma \\
\mathrm{N} / \mathrm{mm}^{2}\end{array}$ & $\eta_{1}$ forH1 & $\eta_{2}$ for $\sigma$ & $\begin{array}{c}\text { Multiresponse } \\
\eta\end{array}$ \\
\hline 1 & 750 & 3000 & -30 & 150 & 464 & -43.522 & 53.3304 & 4.9043 \\
\hline 2 & 750 & 3000 & -30 & 150 & 461 & -43.522 & 53.274 & 4.8761 \\
\hline & & & Average & 150 & 462.5 & & Average & 4.8902 \\
\hline
\end{tabular}


The verification experiment is the final step in Taguchi design. Since the optimum condition of parameter levels was not included in the main experiment, an indirect method was chosen to predict the multiple characteristics. The predicted optimum value of $S / N$ ratio $\left(\eta_{\text {opt }}\right)$ is determined as [23]:

$$
\eta_{\text {opt }}=m+\sum_{j=1}^{p}\left[\left(m_{i, j}\right)_{\max }-m\right]
$$

where, $\left(m_{i, j}\right)_{\max }$ is the $\mathrm{S} / \mathrm{N}$ ratio of optimum level $i$ of parameter $j$ and $p$ is the number of main design parameters that affect the multiple performance. The predicted $\mathrm{S} / \mathrm{N}$ ratio for the optimum laser process parameter levels (LP1, SS3 and FP3) is $4.8899 \mathrm{~dB}$.

The validation experiment was conducted according to the optimal process parameter levels (LP1, SS3 and FP3). Two trials were conducted and the corresponding heat input and tensile strength values were measured. Table $V$ summarizes the experimental condition, the actual and average experimental values of $\mathrm{HI}, \sigma$ and average value of multiresponse $\mathrm{S} / \mathrm{N}$ ratio performance. The average value of heat input and tensile strength are $150 \mathrm{~J} / \mathrm{cm}$ and 462.5 $\mathrm{MPa}$ respectively. The average multiresponse $\mathrm{S} / \mathrm{N}$ ratio for the confirmation experiment is $4.8902 \mathrm{~dB}$.

In order to judge the closeness of observed value of $\mathrm{S} / \mathrm{N}$ ratio with that of the predicted value, the confidence interval value of $\eta_{\text {opt }}$ for the optimum process parameter level combination at $95 \%$ band is determined. The $\mathrm{Cl}$ is given by [24]:

$$
\text { C.I }= \pm \sqrt{\left[F_{\left(1, v_{e}\right)} v_{e}\left(\frac{1}{\eta_{\text {eff }}}+\frac{1}{\eta_{v e r}}\right)\right]}
$$

where, $v_{e}$ is the degrees of freedom for error $=2, F_{\left(1, v_{e}\right)}$ is the $F$ value for $95 \%$ confidence interval $=18.51, v_{e}$ is the variance of error $=$ Mean square error $=0.00016$.

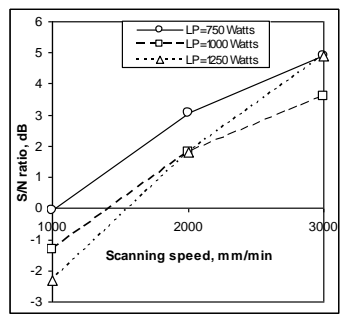

Figure 2: Interaction effect plot of LP and SS on multiresponse S/N ratio of performance characteristics.

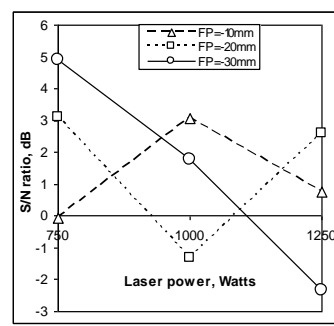

Figure 3: Interaction effect plot of LP and FP multiresponse S/N ratio of performance characteristics.

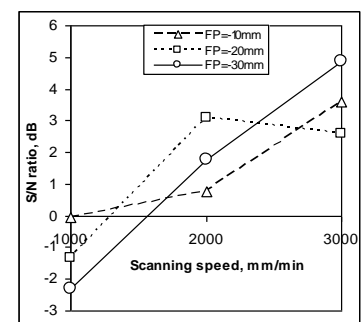

Figure 4: Interaction effect plot of SS and FP on multiresponse $\mathrm{S} / \mathrm{N}$ ratio of performance characteristics. 


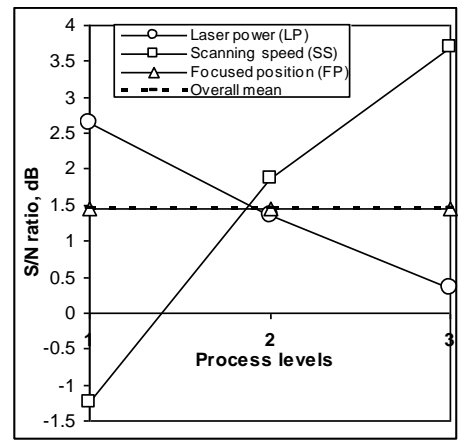

Figure 5: Response graph of control parameters.
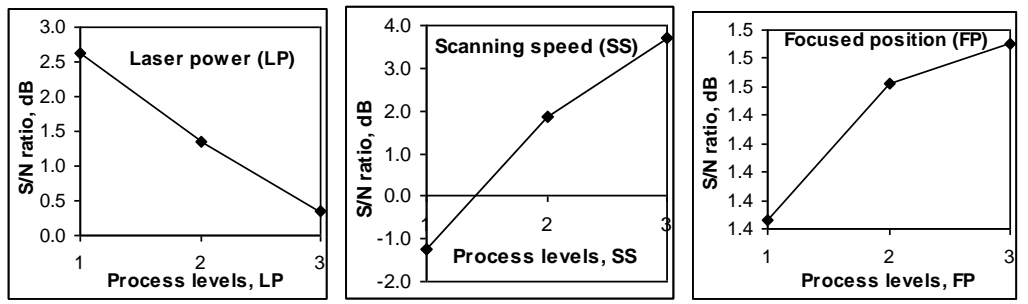

Figure 6: Average values of $\mathrm{S} / \mathrm{N}$ ratio of each process parameter at each levels 1-3.

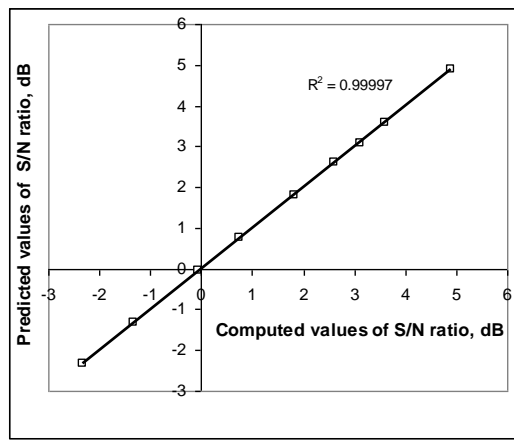

Figure 7: Scatter diagram of multiresponse $\mathrm{S} / \mathrm{N}$ ratio multiperformance characteristics.

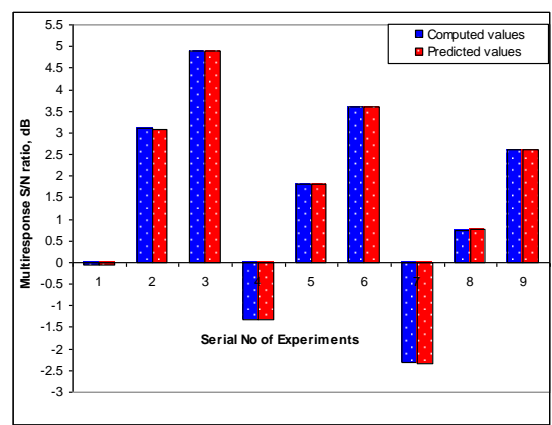

Figure 8: Comparison between computed and predicted values of multiresponse S/N ratio $\eta_{v e r}=\frac{N}{1+v}$

$\mathrm{N}=$ Total trial number of experiments $=9$,

$v=$ Degrees of freedom of p process parameters $=6$,

$\eta_{\text {ver }}$ is the validation test trial number $=2$. 
In the present study, the prediction error i.e. the difference between $\eta_{\text {opt }}$ and $\eta_{\text {obs }}$ is $0.00028 \mathrm{~dB}$, which is within the $\mathrm{Cl}$ value of $\pm 0.0609 \mathrm{~dB}$, and hence, justifying the adequacy of the additivity of the model. Thus, the optimal process parameter level combination for simultaneously minimizing the heat input and maximizing tensile strength is LP1 (750Watts), SS3 $(3000 \mathrm{~mm} / \mathrm{min})$ and FP3 $(-30 \mathrm{~mm})$. Therefore, results revealed the predicted optimal values of tensile strength and heat input of commercially pure titanium sheet produced by laser transformation hardening process are $464 \mathrm{~N} / \mathrm{mm}^{2}$ and $141.667 \mathrm{~J} / \mathrm{cm}$, respectively, for the optimized laser process parameters, $L P=750$ Watts, $S S=3000 \mathrm{~mm} / \mathrm{min}$, and $F P=-30 \mathrm{~mm}$.

\section{CONCLUSIONS}

Taguchi approach with utility concept has been successfully used to determine the best combination values of laser process parameters, such as laser power, scanning speed, and focused position for simultaneously minimizing the heat input and maximizing the tensile strength during laser transformation hardening of commercially pure titanium using Nd:YAG laser. From the analysis of experimental results using $\mathrm{S} / \mathrm{N}$ ratio and ANOVA the following conclusions are made from the current investigation within the ranges of the process parameters selected.

- The results of ANOM indicate that a combination of higher levels of scanning speed and focused position along with laser power in the lower level is necessary for simultaneously minimizing the heat input and maximizing the tensile strength.

- The results of ANOVA clearly indicate that the scanning speed and laser power are the most significant parameters followed by focused position in optimizing the multiple performances.

- The ANOVA also resulted in very small value $6.95 \mathrm{E}-04 \%$ of error, indicating that the interaction effects of process parameters on optimization of multiple performances are absolutely negligible.

- The utility concept is found to be very simple and useful for simultaneous optimization of several performance characteristics.

\section{ACKNOWLEDGMENTS}

The authors are grateful to management of welding Research Institute, BHEL, Tiruchirappalli- 620 014, Tamil Nadu, India for extending the facilities of Laser Materials Processing Laboratory to carryout the research work in the area of laser materials processing. The authors also wish to express their sincere thanks for the constant encouragement received from the faculties of MANIT Bhopal-462051, M.P, India during the course of work.

\section{REFERENCES}

[1] Robinson, J.M.; Van Brussel, B.A.; De Hosson, J.Th.M.; Reed, R.C. (1996). X-ray measurement of residual stresses in laser surface melted Ti-6A1-4V alloy, Materials Science and Engineering, Vol.A208, pp.143 -147

[2] Zhang, S.; Wu, W.T.; Wang, M.C.; Man, H.C.; (2001) In-situ synthesis and wear performance of tic particle reinforced composite coating on alloy ti6al4v, Surface \& Coatings Technology, Vol.138 (1), pp.95-100

[3] Wang, S.H.; Wei, M.D.; Tsay, L.W. (2003).Tensile properties of LBW welds in Ti-6Al-4V alloy at evaluated temperatures below $450^{\circ} \mathrm{C}$, Materials Letter, Vol.57, pp.1815-1823.

[4] Casalino, G.; Curcio, F.; Memola, F.; Minutolo, C. (2005). Investigation on Ti6Al4V laser welding using statistical and Taguchi approaches, J. Materials Processing Technology, Vol.167, pp.422-428

[5] Badkar, D.S.; Pandey, K.S.; Buvanashekaran.G. (2010). Effects of Laser Phase Transformation Hardening Parameters on the Heat Input and Hardened-Bead Profile Quality of Unalloyed Titanium", International Journal of Transactions of Nonferrous Metals Society of China, Volume 20(6), pp.1078-1091 
[6] Padmanaban, G.; Balasubramanian.V. (2010) Optimization of laser beam welding process parameters to attain maximum tensile strength in AZ31B magnesium alloy", Optics \& Laser Technology , Vol.42 (8), pp. 1253-1260

[7] Jang, I.; Lee, K.Y. (2010). Application of robust prediction for a laser-GMA hybrid welding process and parameter optimization of 6061-T6 aluminium alloy", Proceedings of the Institution of Mechanical Engineers, Part B: Journal of Engineering Manufacture, Vol.224, pp.1671-1678

[8] Kamal Kumar Kanaujia, Sahoo, S.K. (2011). An Investigation of Dissimilar Welding Joint of AISI 304L Stainless Steel with Pure Copper by Nd:YAG Pulse Laser: Optimization of Tensile Strength, Thesis submitted to Department of Mechanical Engineering National Institute of Technology, Rourkela, pp.1-76

[9] Anawa, E.M.; Elmabrouk, O.M.; Olabi, A.G. (2009). Optimization of dissimilar joining of titanium / aluminum, Industrial Engineering and Engineering Management, IEEM 2009. IEEE International Conference on 8-11 Dec. 2009 pp. $184-188$

[10] Anawa, E.; Olabi, A.; (2008). Optimization of tensile strength of ferritic/austenitic laser-welded components, Optics and Lasers in Engineering, Vol.46 (8), pp. 571-577

[11] Acherjee, B.; Kuar, A S.; Mitra, S.; Misra, D. (2010). Selection of process parameters for optimizing the weld strength in laser transmission welding of acrylics, Proceedings of the Institution of Mechanical Engineers, Part B: Journal of Engineering Manufacture, Vol.224 (10), pp.1529-1536

[12] Tsung Yuan Kuo.; Huan Chang Lin.; Tze Yuan Liao.; Chih Hua Kuo.; Tsung Jen Han. (2011).Taguchi Method for 304 Stainless Steel Nd-YAG Laser Beam Welding, Advanced Materials Research, Vol.287-290, pp.3112-3115

[13] Hsuan Liang Lin.; Chang Pin Chou. (2007). Modeling and optimization of Nd:YAG laser microweld process using Taguchi Method and a neural network", The International Journal of Advanced Manufacturing Technology, Vol.37 (5-6), pp.513-522

[14] Taguchi, G. (1986). Introduction to Quality Engineering, Asian Productivity Organization.

[15] Taguchi, G. (1987). Systems of Experimental Design, Unipub Kraus International Publishers, New York

[16] Ross, P.J. (1996). Taguchi Techniques for Quality Engineering. 2nd edn. McGraw-Hill, New York

[17] Park, J.H.; Yang, K.M.; Kang, K.S. (2005). A quality function deployment methodology with signal and noise ratio for improvement of Wassermann weights. International Journal of Advanced Manufacturing Technology, Vol.26, pp.631-637

[18] Tong, L.I.; Wang, C.H.; Chen, H.C. (2005). Optimization of multiple responses using principal component analysis and technique for order preference by similarity to ideal solution," Int $\mathrm{J}$ Advanced Manufacturing Technology, Vol. 27, pp. 407-414

[19] Palanikumar, K. (2008). Application of Taguchi and response surface methodologies for surface roughness in machining glass fiber reinforced plastics by PCD tooling, Int J Advanced Manufacturing Technology, Vol. 36, pp. 19-27

[20] Kumar, P.; Barua, P.B.; Gaindhar, J.L. (2000). Quality optimization (multi-characteristic) through Taguchi's technique and utility concept, Quality and Reliability Engineering International, Vol.16, pp 475-485

[21] Walia, R.S.; Shan, H.S.; Kumar, P. (2006). Multi-Response Optimization of CFAAFM Process through Taguchi Method and Utility Concept", Materials and Manufacturing Processes, Vol. 21, pp. 907-914

[22] Taguchi, G. (1986), Introduction to Quality Engineering, Asian Productivity Organization.

[23] Casalino, G.; Curcio, F.; Memola F.; Minutolo, C. (2005). Investigation on Ti6Al4V laser welding using statistical and Taguchi approaches, J. Materials Processing Technology, Vol.167, pp. 422-428

[24] Lima, M.S.F. (2005). Laser beam welding of titanium nitride coated titanium using pulseshaping, Materials Research, Vol.8, pp. 323-328 